\title{
Epithelium-Free Area in the Thymic Cortex of Rats
}

\author{
JOOST P. BRUIJNTJES, + C. FRIEKE KUPER, ${ }^{*} \ddagger$ JOKE E. ROBINSON, $\ddagger$ and HENK-JAN SCHUURMAN $\$ \S$
}

+TNO Toxicology and Nutrition Institute, Zeist, The Netherlands.

$\ddagger$ National Institute of Public Health and Environmental Protection, Bilthoven, The Netherlands.

$\S$ Departments of Internal Medicine and Pathology, University Hospital Utrecht, Utrecht, The Netherlands.

The histology of epithelium-free areas in the subcapsular region of the thymus was studied in Wistar rats. Lymphocytes in these areas were CD4/CD8 double-positive, TCR $\alpha / \beta$ positive in low intensity, and in CD5 labeling either negative or positive in low intensity. There was a high proliferative activity as assessed by bromodeoxyuridine incorporation in vivo and detected by immunohistochemistry. Various macrophage types were observed. They were either large and round to slightly dendritic, or small and dendritic. Most large cells were positive for MHC Class II, and labeled by the antimacrophage antibodies ED1 and ED2. A few cells were strongly positive for Sudan black, Oil red $\mathrm{O}$, nonspecific esterase, and acid phosphatase; they resembled the large rounded macrophages in the corticomedullary zone, although their MHC Class II and ED2 staining was more intense. A few cells showed features of tingible body macrophages, as they contained cellular debris.

Serial sections showed that epithelium-free areas run from the subcapsular area to deep in the cortex, and often border the medulla. This opens the opportunity for immature lymphocytes to move into the medulla and corticomedullary zone without contacting and potential selection with cortical stromal elements other than macrophages in the epithelium-free areas. In this case, the epithelium-free areas may offer a separate intrathymic pathway for T lymphocytes.

KEYWORDS: Epithelium-free compartment, thymus cortex, thymus subcapsule, histochemistry, rat, lymphocyte differentiation.

\section{INTRODUCTION}

The thymus harbors various compartments or microenvironments, based on lymphoid- and nonlymphoid-cell characteristics. Among these are areas devoid of stromal elements. Adjacent to the capsule and septa of the thymus, areas can be discerned where there are no epithelial cells. These so-called epithelium-free areas (EFA) show an abundance of lymphocytes (rat: Duijvestijn et al. 1982; mouse: Van Ewijk, 1984; Godfrey et al., 1990; man: epithelium-free areas in the inner cortex; Von Gaudecker, 1986). The occurrence and extent of these EFA varies between strains of rats. In the thymus of WAG/Rij rats, such areas have not been observed, whereas in diabetes-prone (DP) and diabetes-resistant (DR) BB rats, they

*Corresponding author. Present address: National Institute of Public Health and Environmental Protection, P.O. Box 1, 3720 BA Bilthoven, The Netherlands. make up 5\% and $3 \%$ of the thymic volume, respectively (Rozing et al., 1989). The thymus of BB rats also showed EFA in the medulla and in the corticomedullary region (CMR). Medullary EFA were also found immediately after and during recovery from Cyclosporin treatment (Schuurman et al., 1990). It is questionable whether the areas in the cortex of untreated, healthy rats represent a similar histologic entity as EFA in the medulla and CMR of $B B$ rats and rats after Cyclosporin treatment. This aside, EFA is evidently different from the perivascular space (PVS). PVS are connective tissue regions, containing collagen and matrix, and are as such considered as an extrathymic area (Christensen, 1952; Kendall, 1989). They are lined by fenestrated sheaths of type- 1 epithelial cells on a basal lamina.

The occurrence of EFA is dependent on age. EFA in young adult Wistar rats can be fairly extensive, and in rats over 17 months of age, such 
areas have not been found (Kuper et al., in press). Instead, perivascular spaces, especially in the CMR, were more prominent. A (transient) increase in PVS volume has also been demonstrated in the human thymus (Steinman, 1986).

The characteristics of EFA were not clearly defined, and their function, if there is any, is unknown. They may be reservoirs for lymphocytes (Van Ewijk, 1984) or proliferation sites of lymphocytes (Duijvestijn et al., 1982; Godfrey et al., 1990). We therefore performed an enzymeand immunohistochemical study in rats to investigate the lymphoid and nonlymphoid elements in the EFA of the thymus cortex, in order to elucidate possible functions of the compartment. To investigate the proliferative activity in the areas, the thymidine analog bromodeoxyuridine (BrdU) was injected in rats, and the presence of BrdU in thymus was detected immunohistochemically.

TABLE 1

Mouse monoclonal and rabbit polyclonal antibodies used in this study

\begin{tabular}{|c|c|c|c|}
\hline Monoclonal & Specificity for thymus cells & Source $^{a}$ & $\operatorname{Refs}^{b}$ \\
\hline W3/25 & CD4, subset thymocytes & Serotec & 1 \\
\hline MRC OX19 & CD5, subset thymocytes & Serotec & 2 \\
\hline MRC OX8 & CD8, subset thymocytes & Serotec & 1 \\
\hline R73 & $\begin{array}{l}\text { T-cell receptor } \alpha / \beta \text { chain } \\
\text { subset thymocytes }\end{array}$ & & 3 \\
\hline HIS44 & $\begin{array}{l}\text { Most cortical lymphocytes, } \\
\text { some medullary } \\
\text { lymphocytes }\end{array}$ & & 4 \\
\hline MRC OX4 & $\begin{array}{l}\text { MHC Class II, cortical } \\
\text { and medullary } \\
\text { epithelium, IDCs, subset } \\
\text { macrophages }\end{array}$ & Serotec & 5 \\
\hline ED1 & $\begin{array}{l}\text { Majority of macrophages, } \\
\text { IDCs and monocytes }\end{array}$ & & 6 \\
\hline ED2 & Subset cortical macrophages & & 6 \\
\hline RCK 105 & $\begin{array}{l}\text { Keratin } 7(54 \mathrm{KD}) \text {, cortical } \\
\text { epithelial cells, and some } \\
\text { medullary epithelial cells }\end{array}$ & & $7,8,9$ \\
\hline RGE 53 & $\begin{array}{l}\text { Keratin } 18 \text { (45KD), cortical } \\
\text { epithelial cells, and some } \\
\text { medullary epithelial cells }\end{array}$ & & $7,8,9$ \\
\hline HIS39 & $\begin{array}{l}\text { Subcapsular and medullary } \\
\text { epithelium }\end{array}$ & & 10 \\
\hline anti-BrdU & $\begin{array}{l}\text { Thymidine analog } \\
\text { bromodeoxyuridine }\end{array}$ & Dakopatts & 11 \\
\hline HIS14 & All B lymphocytes & & 12 \\
\hline Polyclonal & Directed against & Source & \\
\hline $\begin{array}{l}\text { Anti- } \\
\text { Laminin }\end{array}$ & Laminin & Dakopatts & \\
\hline
\end{tabular}

Commerical sources; for noncommercial sóurces, see Acknowledgments. 'References: 1: Williams et al., 1977; 2: Dallman et al., 1984; 3: Hunig et al., 1989; 4 Kampinga, 1990; 5: McMaster and Williams, 1979; 6: Dijkstra et al., 1985; 7: Moll et al., 1982; 8: Ramaekers et al., 1983; 9: Ramaekers et al., 1987; 10: Kampinga et al., 1987; 11: Gratzner, 1982; 12: Kroese et al., 1987.

\section{RESULTS}

\section{General Histology}

Along the capsule and septa, areas were found that, in H\&E-stained sections, were prominent due to their high number of lymphocytes but in which no epithelial cells are evident. The areas were negative for keratin (antibodies: see Table 1; Fig. 1). MHC Class II staining was also negative except for single cells (Figs. 2, and 8; see also what follows under "Macrophages"). Almost no laminin was found, either within the areas or between the areas and the epithelium-containing thymic tissue (Fig. 3). Vascularization was virtually absent. The subcapsular epithelial layer was found between these cortical epithelium-free areas (EFA) and the connective tissue of capsule and septa (Fig. 4). Some of the EFA ran from the capsule to the medulla. Serial sections from one thymus often showed medullary buds bordering the EFA (Fig. 2). The medullary epithelial network extended with cell processes into the areas.

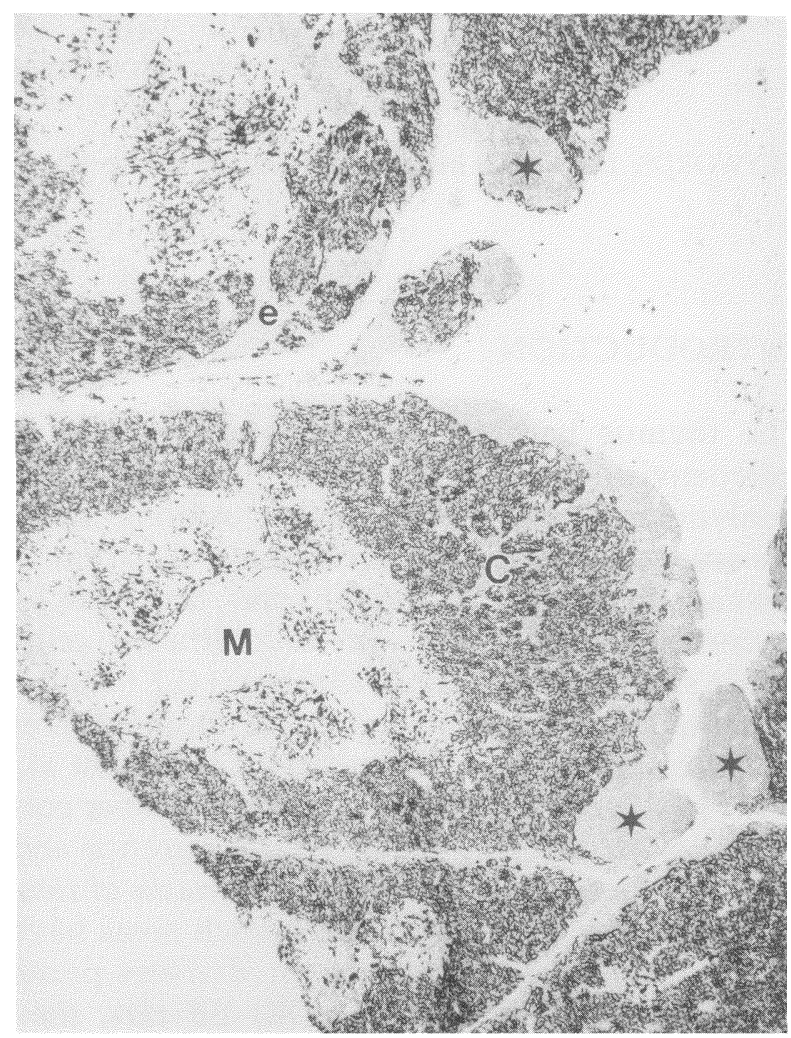

FIGURE 1. A low-power view of the thymus, immunostained for keratin (RGE 53). Several EFA are transected (*), mostly restricted to the outer cortex. One EFA transection (e) extends to the medulla. M: medulla; C: cortex. $(\times 16)$. 
The bordering cortical epithelium was mostly rounded off, with occasionally some dendritic processes extending into the EFA (Figs. 1, 2, and 7). In H\&E-stained sections, the flattened cortical epithelium gave the impression of demarcating the rest of the cortex from the EFA. An effect of sex on the presence and size of EFA was not apparent, although it has not been examined systematically.

\section{Lymphocytes in EFA}

Staining of serial sections showed that the lymphocytes in the EFA were immunoreactive for CD4 and CD8 (Fig. 5). Because both CD4 and CD8 antibodies labeled most cells, the lymphocytes were considered CD4/CD8 double-positive. In CD5 immunolabeling, cells showed a low intensity of labeling or were negative. In labeling with an anti-TCR $\alpha / \beta$ antibody, most cells were labeled in low intensity. This labeling intensity for TCR $\alpha / \beta$ may be lower on EFA lymphocytes than on other cortical lymphocytes because immunostaining for TCR $\alpha / \beta$ did not enable a distinction between EFA and the surrounding cortex despite the higher number of lymphocytes in EFA. Staining for HIS44 was variable: some cells stained as intensely as other cortical lymphocytes, whereas others were labeled by HIS44 in low intensity (Fig. 6). Occasionally, a few cells were immunoreactive for total $\mathrm{Ig}$ ( $\mathrm{Ig}$, 7S fraction) and HIS14, but negative for IgM.

The density of BrdU-positive cells was high in the EFA, especially at the periphery, comparable to the subcapsular zone; see Figs. 7(A) and (B). The remaining cortex showed somewhat less positivity, except at the CMR. There were some positive cells in the medulla.

\section{Macrophages in EFA}

The EFA harbored different types of macrophages, as judged by cell morphology and immunologic phenotyping. The various macrophage types could not be determined precisely in single- or two-color serial sections, because not all combinations were suitable/successful for double staining, and some overlap between the types was to be expected. In H\&E-stained sections, large rounded cells were observed between the lymphocytes, which had an irregularly shaped nucleus and vacuolated cytoplasm, and occasionally contained cellular debris.

MHC Class-II immunostaining revealed large

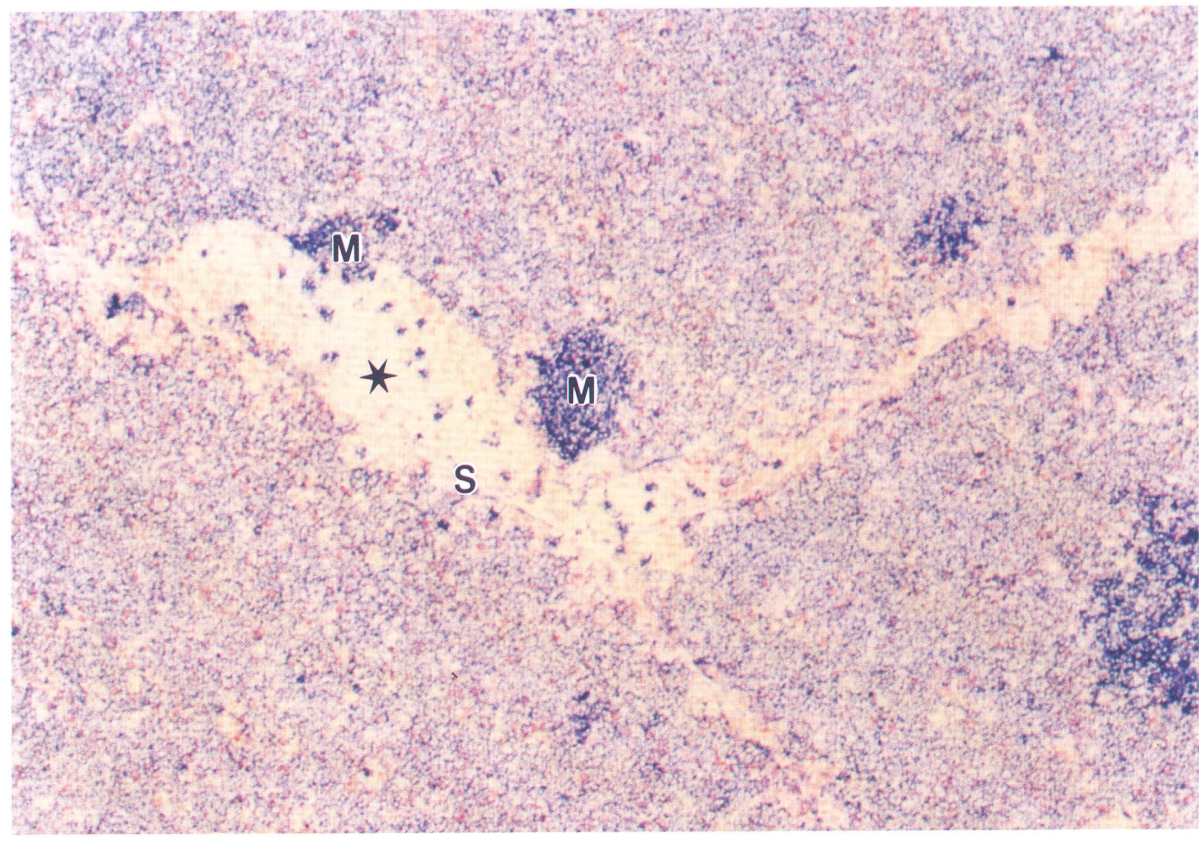

FIGURE 2. (See Colour Plate XII at the back of this publication). Two-color immunostaining against Class-II antigen (blue) and BrdU (red): EFA $\left(^{*}\right)$ is negative for Class II except for macrophages. Two medullary buds (M) with confluent Class-II staining border the EFA. S: septum. ( $\times 90)$. 


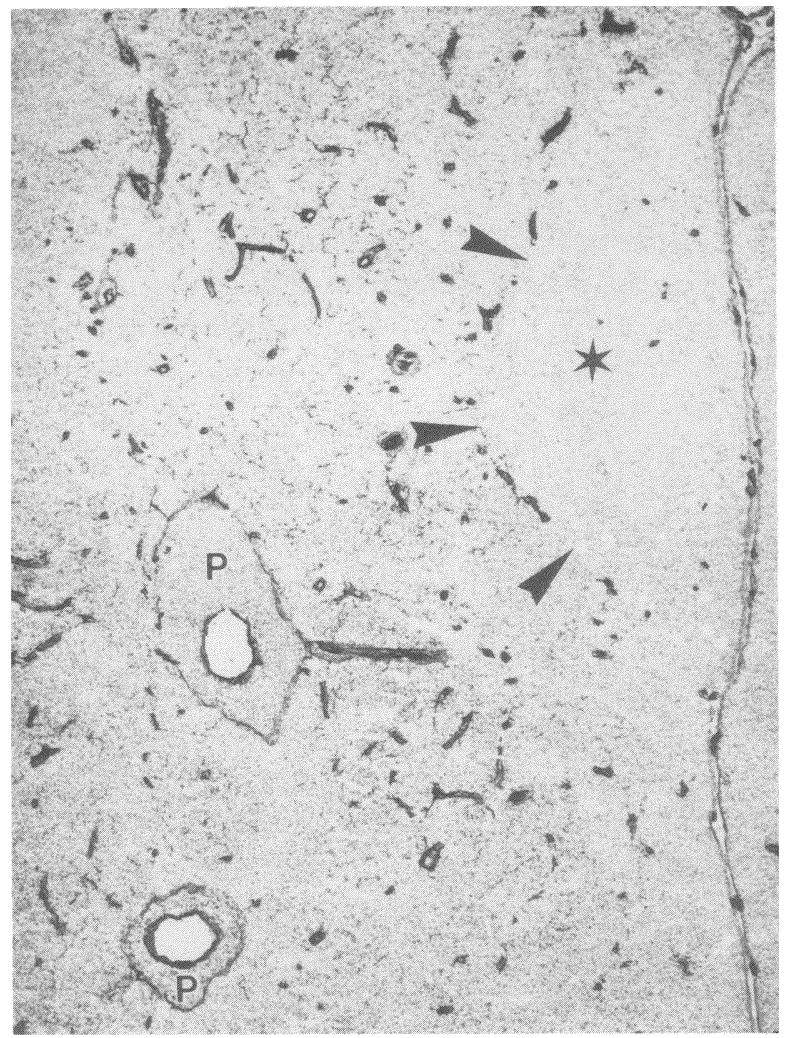

FIGURE 3. Immunostaining for laminin. EFA $\left(^{*}\right)$ is not bordered by a laminin layer (arrowheads indicate EFA border). Perivascular spaces (PVS or P) with a laminin layer between the PBS $(P)$ and thymic epithelium are also shown here. $(\times 60)$.

cells with a rounded to dendritic morphology and small dendritic macrophage like cells (Figs. 2 and 8). The large cells showed a confluent ClassII reactivity, comparable to that of medullary IDCs and of single cells in the cortex. ED1 staining (panmacrophage marker, Table 1) showed predominantly large cells with a rounded to slightly dendritic morphology and a few small dendritic cells. There were some large cells with a rounded morphology, and a few small dendritic cells that were ED1-positive but negative or faintly immunoreactive for MHC Class II (Fig. 8). Most ED2-positive cells were large cells with a rounded to dendritic morphology (ED2, cortical macrophage marker, Table 1). In number and cell contour, these cells were comparable to cells identified in ED1 staining. ED2 staining of the large cells was more intense than in the rest of the cortex. In two-color immunohistochemistry for ED1 and ED2, only a few large and small cells were ED1 positive/ED2 negative (Fig. 9).

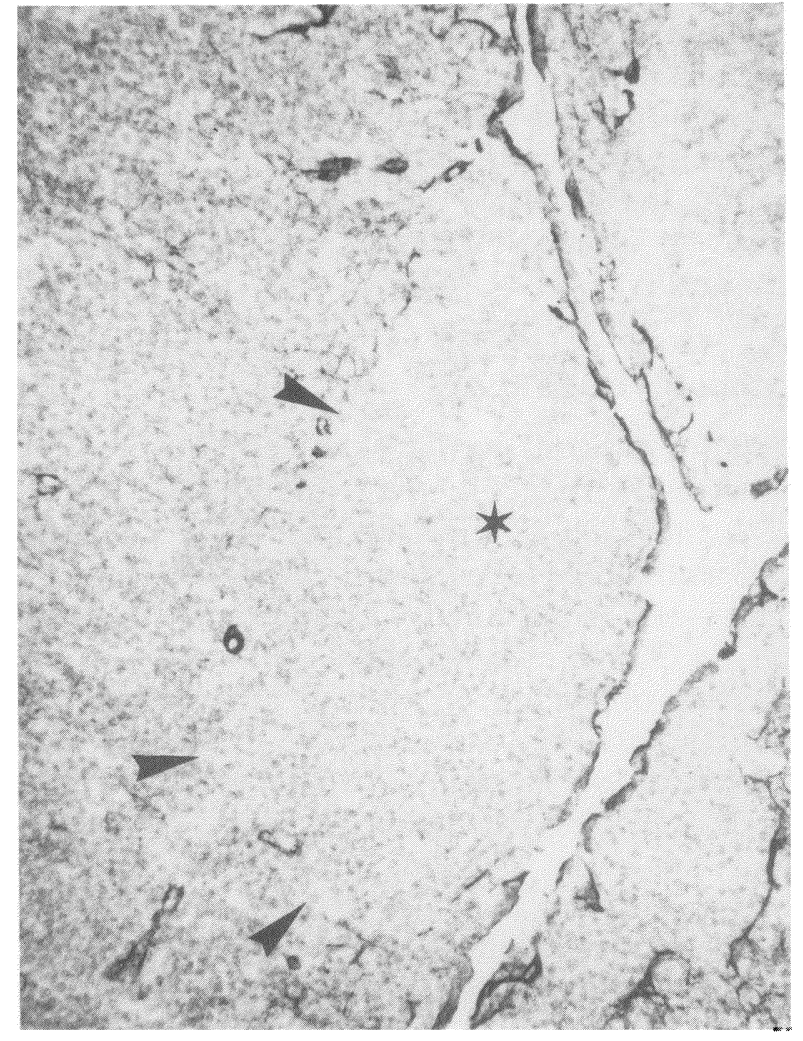

FIGURE 4. Immunostaining for HIS39. The subcapsular epithelium borders EFA ${ }^{*}$ ) (arrowheads indicate EFA border). $(\times 160)$.

A few large, rounded cells were strongly positive for Oil red O, Sudan Black, nonspecific esterase (NSE; Fig. 10) and acid phosphatase (AP). Other macrophages were weakly positive for NSE and AP.

\section{DISCUSSION}

Epithelial-free areas (EFA) are found in the outer cortex of the thymus, mainly immediately bordering the subcapsular epithelial-cell layer. They can run deep into the cortex and even reach the medulla. At other sites, medullary buds contact the EFA. Immediate contact between lymphocytes in EFA and cortical and medullary epithelium is feasible, because no basal lamina and connective tissue are found between the epithelium and the EFA. Moreover, in keratin and MHC Class-II labeling, the medullary epithelial lining and, at some places, also the cortical epi- 


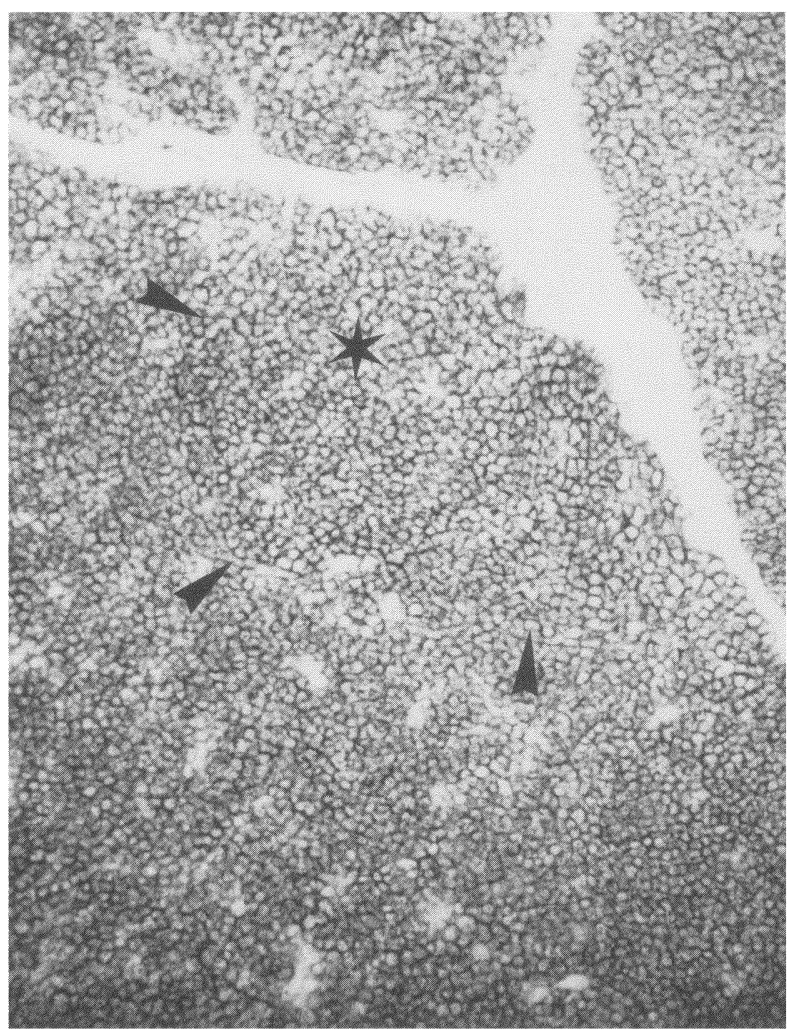

FIGURE 5. Immunostaining for CD8 (OX8). CD8 antibody labeled almost all cells in EFA ${ }^{*}$; arrowheads indicate EFA border). $(\times 160)$.

thelial lining with the EFA suggest that there is free cell movement of lymphocytes between the EFA and the thymic epithelial network. In addition, free cell movement between EFA and CMR appears possible (Figs. 2 and 7).

Serial staining with $\mathrm{CD} 4$ and $\mathrm{CD} 8$ suggests that the predominant lymphocyte is CD4/CD8 double-positive. This is in accordance with findings of Godfrey et al. (1990) and Rozing et al. (1989). EFA also contain TCR $\alpha / \beta$ positive cells. This implies that lymphocytes in the EFA already passed the first intrathymic development, including TCR gene rearrangement. Godfrey et al. (1990) have suggested that the EFA are isolated "bags" of CD4+/CD8+, proliferating lymphocytes before they contact the thymic stroma. Proliferation in EFA is evident from BrdU labeling, performed in double staining with keratin or MHC Class II and BrdU. Moreover, EFA contain several lymphocytes that are either strongly positive or faintly positive for HIS44. Kampinga (1990) has suggested that lymphocytes lose this

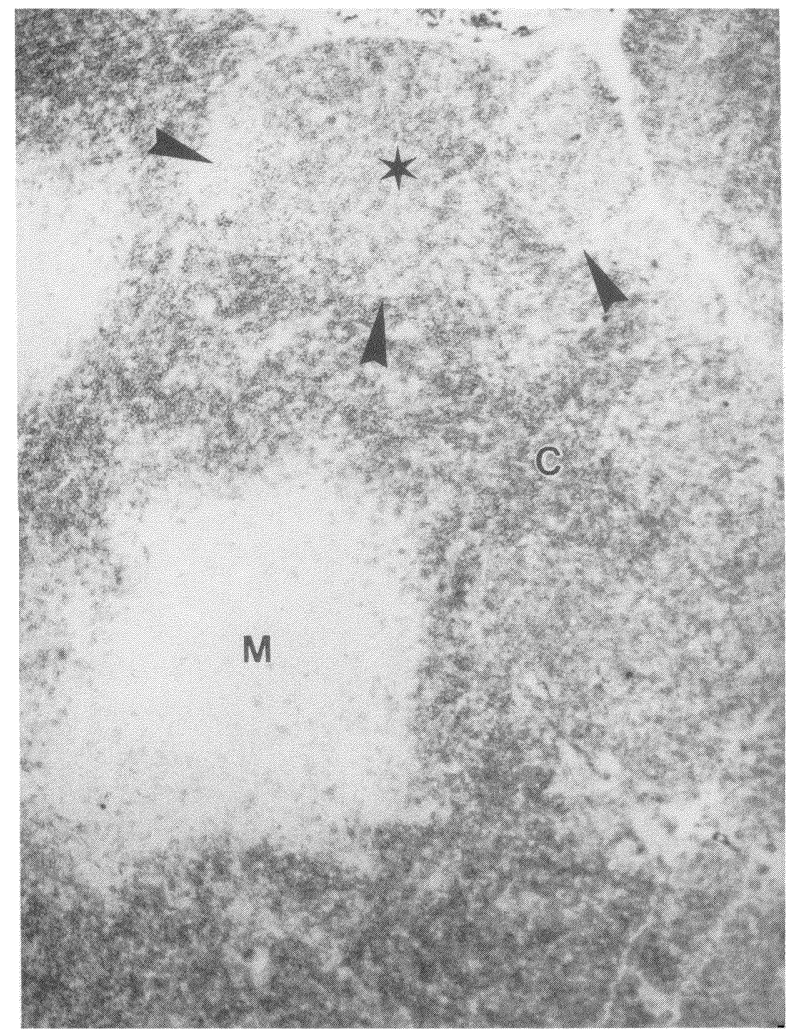

FIGURE 6. Immunostaining for HIS44. Lymphocytes in EFA (*; arrowheads indicate EFA border) are variably stained. M: medulla; C: cortex. $(\times 160)$.

marker during intrathymic proliferation. Following his suggestion, the presence of this marker indicates that lymphocytes in the EFA stay a while before proliferation, or stay sufficiently long after proliferation to regain the marker. Boyd and Hugo (1991) have hypothesized that cells in EFA are accumulations of double-positive lymphocytes, which are not under the influence of positive selection, and subsequently die by apoptosis.

In EFA, macrophages with features of TBM are not frequent. However, under "stressfull" conditions, for example, after dexamethason administration, TBM may accumulate in EFA (Fig. 11; unpublished results). Moreover, the large rounded macrophages in EFA, which are strongly positive for Oil red O, NSE, AP and Sudan Black and resemble CMR macrophages (Milicevic et al., 1987; Milicevic and Milicevic, 1989), might be precursors of tingible body macrophages (TBM), because they sometimes contain nuclear debris. Aggregates of the CMR macro- 

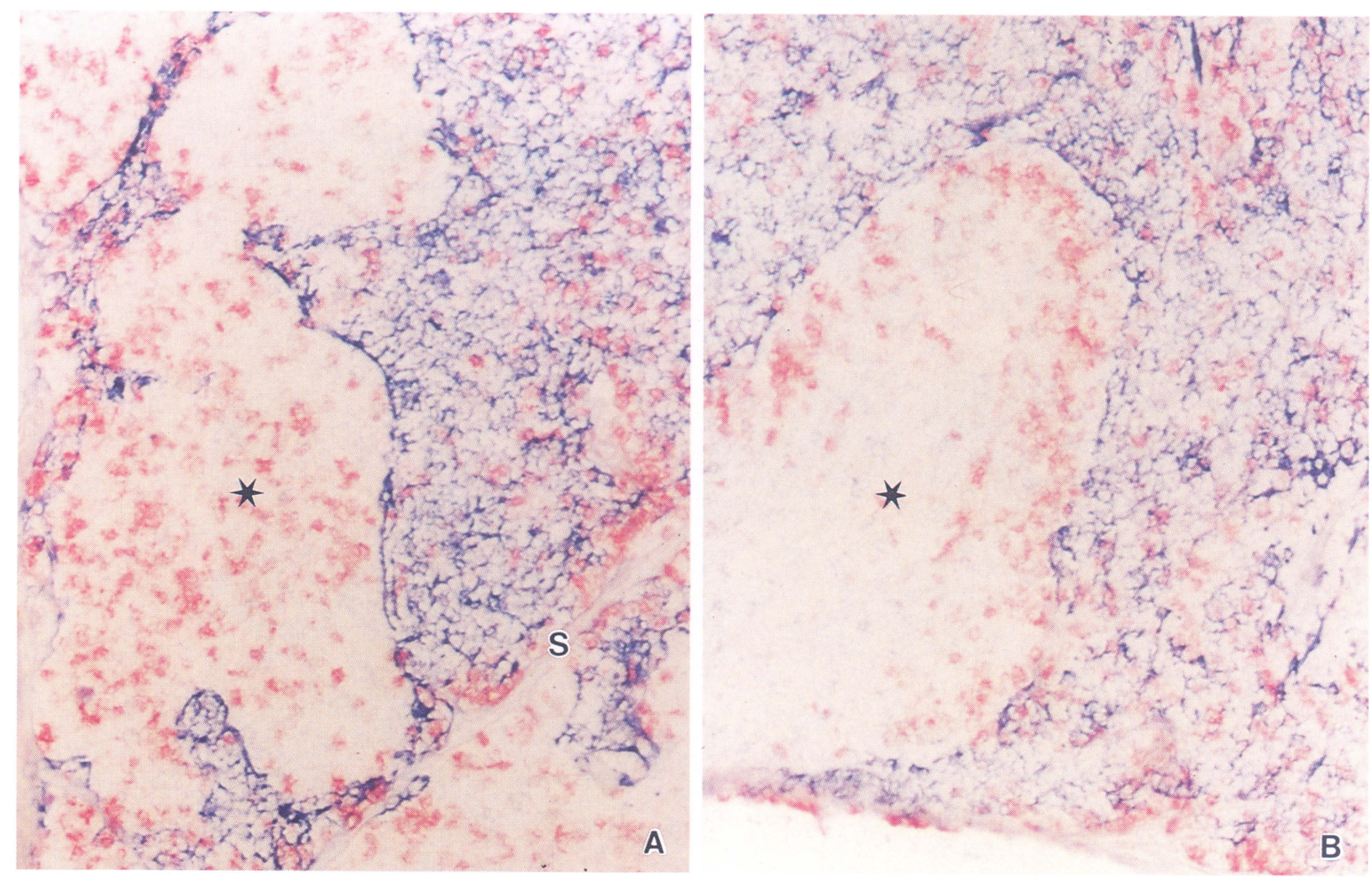

FIGURE 7. (See Colour Plate XIII at the back of this publication). Two-color immunstaining against BrdU (red) and keratin (HCK105; blue). (A) BrdU positivity throughout EFA $\left({ }^{*}\right) ; \times 180$. (B) BrdU positivity predominantly along the border of EFA $(*)$ with cortical and medullary epithelium; $(\times 180)$.

phage-resembling cells were observed in the EFA of the thymus from rats that were treated with high doses of cyclosporin A (Fig. 12; unpublished observations). Remarkably, intracellular nuclear remnants were rarely seen. Cyclosporin reduces thymocytes apoptosis (Shi et al., 1989). This suggests that these macrophages are still attracted to EFA but do not phagocytose any more. As a consequence, immature lymphocytes may enter the periphery without having been subjected to selection. In this case, they may mediate autoimmune reactions visualized by GVH reactions, induced by cyclosporin. This is in accordance with the suggestion of Rozing et al. (1989) that EFA in BB rats are responsible for the generation of autoreactive cells against $\beta$ cells in the pancreas.

There are three arguments that make it difficult to consider EFA as waiting rooms for negatively selected cells. First, Wistar rats have extensive EFA, but have to our knowledge a low incidence, if any, of autoimmune phenomena. This indicates that (a) EFA in Wistar rats, in contrast to BB rats, is an effective way of dealing with potentially autoreactive cells, because EFA in Wistar rats is not similar to EFA in BB rats, or that (b) EFA has other functions than those mentioned before.

Second, such a passive function for EFA as a waiting room of lymphocytes that are to be negatively selected is in contrast with the complex microenvironment, that is, the presence of various types of Class II-negative as well as Class II-positive macrophages, including CMR-like macrophages. The function of these various macrophage cell types is not precisely known. Instead of being precursors of TBM, Milicevic et al. (1987) argued that the CMR macrophages play a role in controlling the proliferation of thymocytes. When related to the model of nickel chloride-treated thymus, they should be considered as reflecting thymic regeneration instead of degeneration (Milicevic and Milicevic, 1989). 


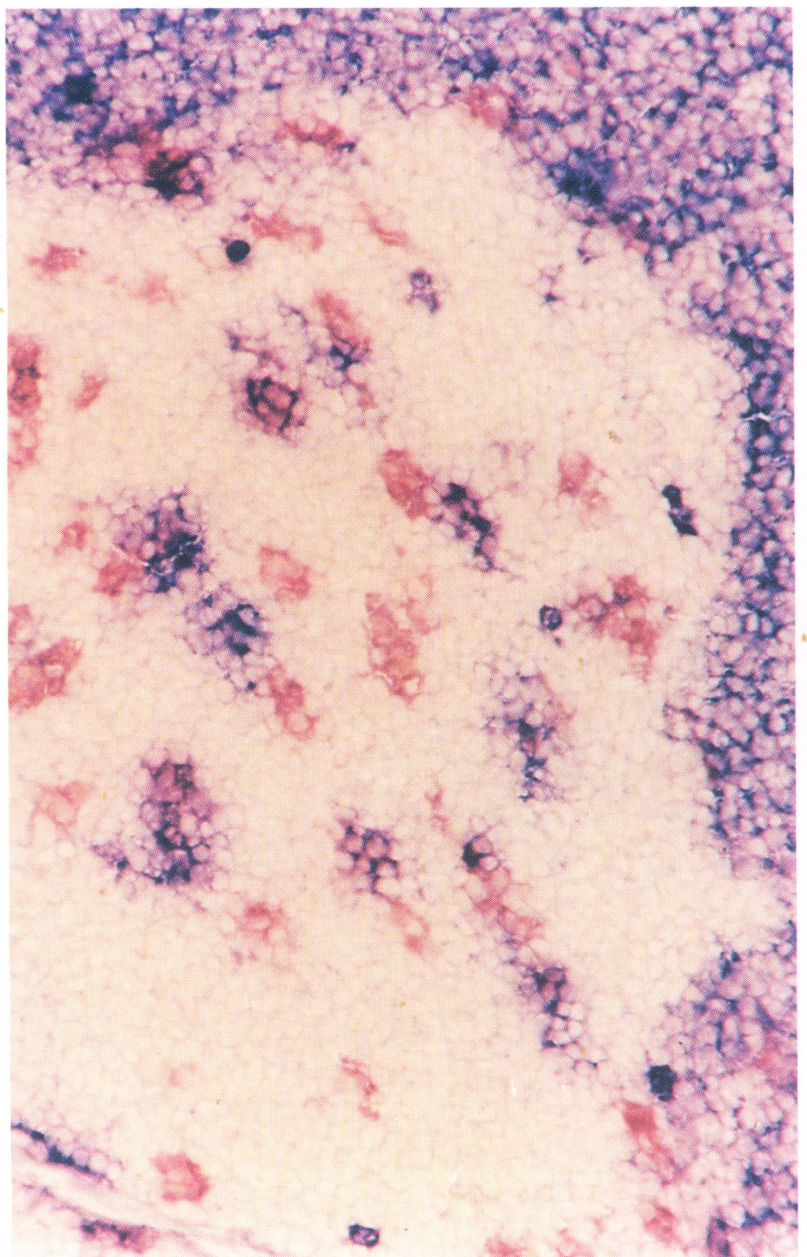

FIGURE 8. (See Colour Plate XIV at the back of this publication). Two-color immunostaining for MHC Class II (blue) and ED1 (red). Some macrophages are positive for ED1 and negative or weakly positive for MHC Class II. $(\times 360)$.

This consideration is in accordance with the extensive EFA seen during recovery from stress (unpublished observations) and during recovery from cyclosporin (Schuurman et al., 1990); it also explains the high proliferation rate in EFA.

Third, the close presence of medulla and CMR to EFA appears to present an unwanted risk, namely, that cells to be negatively selected may enter the periphery via medulla and CMR.

In summary, EFA appears to be a thymic compartment that provides a complex microenvironment for intrathymic lymphocytes. It may provide a pathway for immature double-positive lymphocytes that are observed in the medulla. It may also be a reservoir of lymphocytes awaiting either positive or negative selection. The fate of

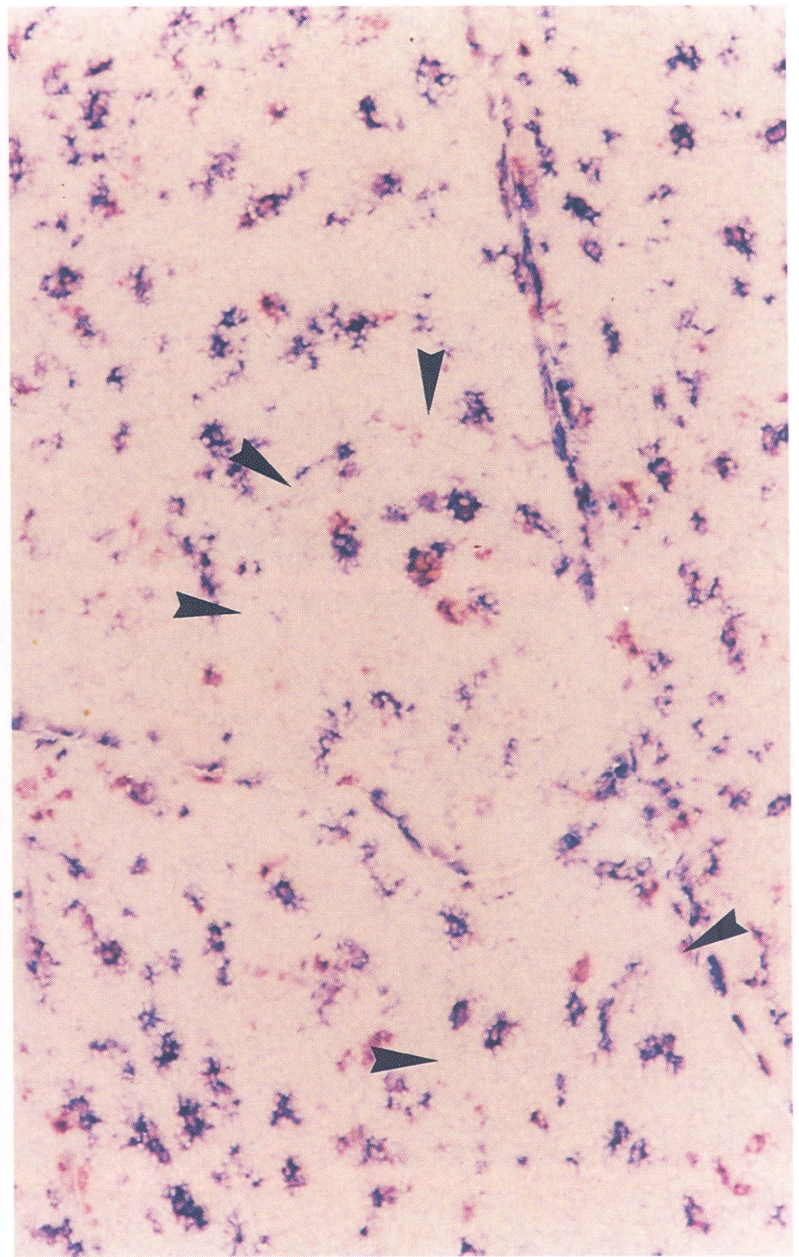

FIGURE 9. (See Colour Plate XV at the back of this publication). Two-color immunostaining for ED1 (red) and ED2 (blue). Most macrophages in EFA (two EFAs are shown here; arrowheads indicate border) are double positive. $(\times 180)$.

the EFA lymphocytes may then depend on the types of macrophages in the EFA and the thymic epithelium lining the EFA. In considering the processes of T-lymphocyte precursors during the intrathymic sojourn, one should be aware that part of these processes can occur in a microenvironment that does not resemble the classical compartments of subcapsule, cortex, and medulla.

\section{MATERIALS AND METHODS}

\section{Animals}

Wistar (Cpb:WU, Wistar random $\mathrm{RTI}^{\mathrm{u}}$ ) rats 

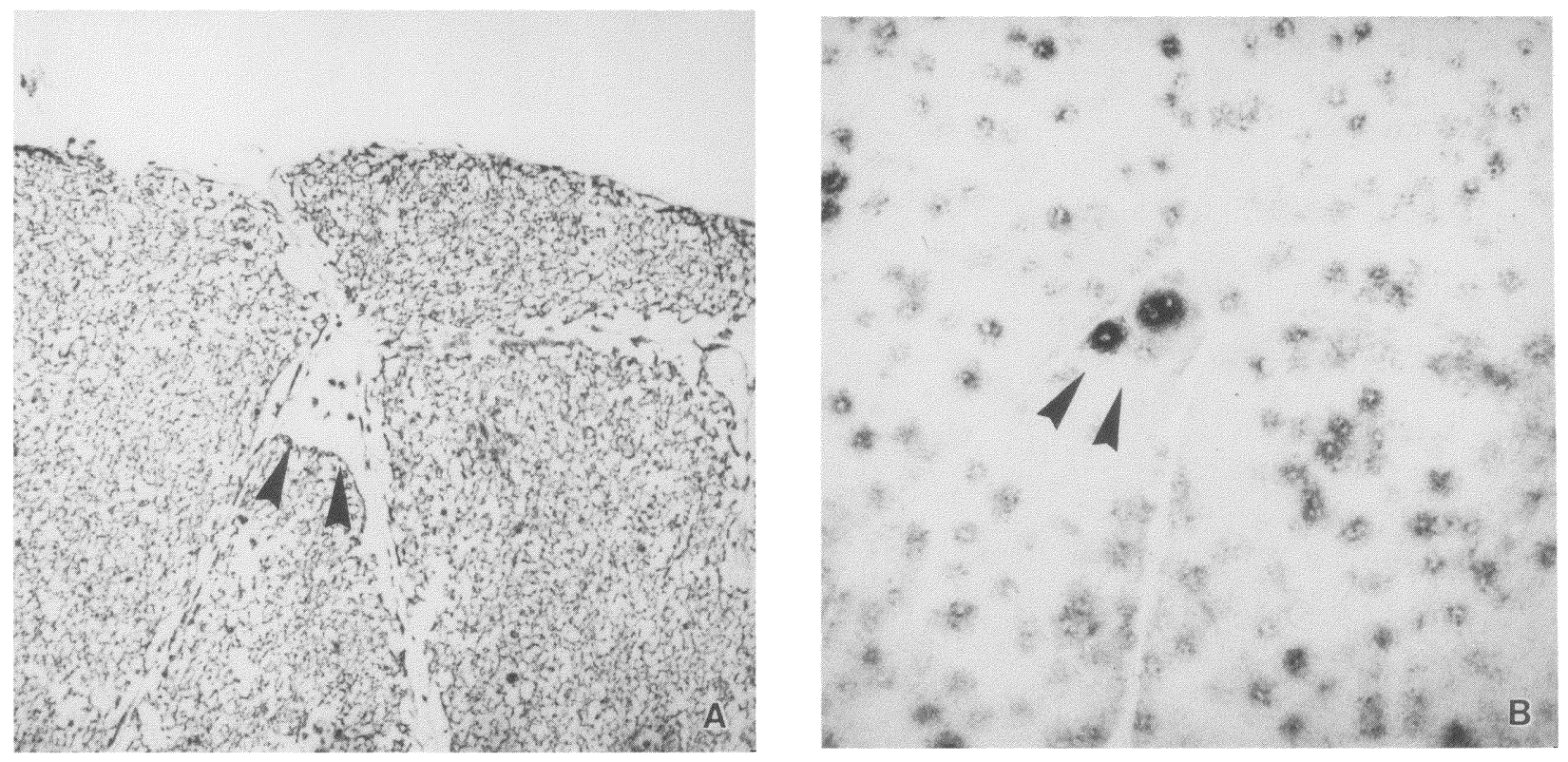

FIGURE 10. Semiserial (1 intervening section omitted) sections of EFA (arrowheads) with a few cells positive for (A), MHC Class-II immunostaining, and (B) strongly positive for nonspecific esterase enzyme-histochemical staining. $(\times 70)$.

between 8 to 11 weeks old were used. They were kept under conventional laboratory conditions.

\section{Tissue Sampling and Preparation}

Part of the animals were intraperitoneally injected with $15 \mathrm{mg} / \mathrm{kg}$ body weight Bromodeoxyuridine, $2 \mathrm{hr}$ before sacrifice. All animals were anesthetized with ether, and bled to death via the abdominal aortia. The thymus was removed, fixed in neutral, phosphate-buffered $4 \%$ solution of formaldehyde or snap-frozen in isopentance in liquid nitrogen, and stored at $-80^{\circ} \mathrm{C}$. Formaldehyde-fixed tissues were embedded in paraffin, sectioned at $5 \mu \mathrm{m}$, and stained with H\&E. Cryostat sections $(5-7 \mu \mathrm{m})$ were stained with oil red $\mathrm{O}$ and Sudan Black (Pearse, 1968) for lipids.

\section{Immunohistochemistry}

Cryostat sections (5-7 $\mu \mathrm{m}$ ) from the thymus were air dried on glass slides, and fixed for $10 \mathrm{~min}$ in acetone. Thereafter, they were rinsed in phosphate-buffered saline (PBS, $0.01 \mathrm{M}, \mathrm{pH}$ 7.4) and preincubated with $10 \%$ normal rabbit serum for $20 \mathrm{~min}$. Serial sections were incubated for $60 \mathrm{~min}$ with one of the monoclonal or polyclonal antibodies listed in Table 1 . The sections were then rinsed in PBS and layered for $30 \mathrm{~min}$ with a peroxidase-conjugated rabbit antimouse $\mathrm{Ig}$ (RAMPO, Dakopatts, Denmark), which was diluted in PBS with 4\% normal rat serum. The sections were subsequently rinsed in PBS and Tris $/ \mathrm{HCl}(0.05 \mathrm{M}, \mathrm{pH} 7.6)$ and finally incubated with the chromogen 3'3'-diaminobenzidine-tetrahydrochloride (Sigma) in a concentration of $0.5 \mathrm{mg} / \mathrm{ml}$ in Tris $/ \mathrm{HCl}$ containing $0.01 \% \mathrm{H}_{2} \mathrm{O}_{2}$ for $10 \mathrm{~min}$. The whole procedure was carried out at room temperature. Most sections were slightly counterstained with haematoxylin. Control slides were incubated with the conjugated Ig (RAMPO), PBS, or the chromogen only. No labeling was observed except for a few polymorphonuclear granulocytes when present.

Two-color immunostaining was performed as follows. Sections were incubated with one of the antibodies listed in Table 1, for $60 \mathrm{~min}$. They were rinsed in PBS, and thereafter incubated for $30 \mathrm{~min}$ with alkaline phosphatase-conjugated rabbit antimouse immunoglobulins (RAMPh, Dakopatts, Denmark). After rinsing with PBS and Tris $/ \mathrm{HCl}$, the sections were incubated with the chromogen naphthol AS-MX phosphate and Fast Blue BB salt for about $15 \mathrm{~min}$. The slides were 


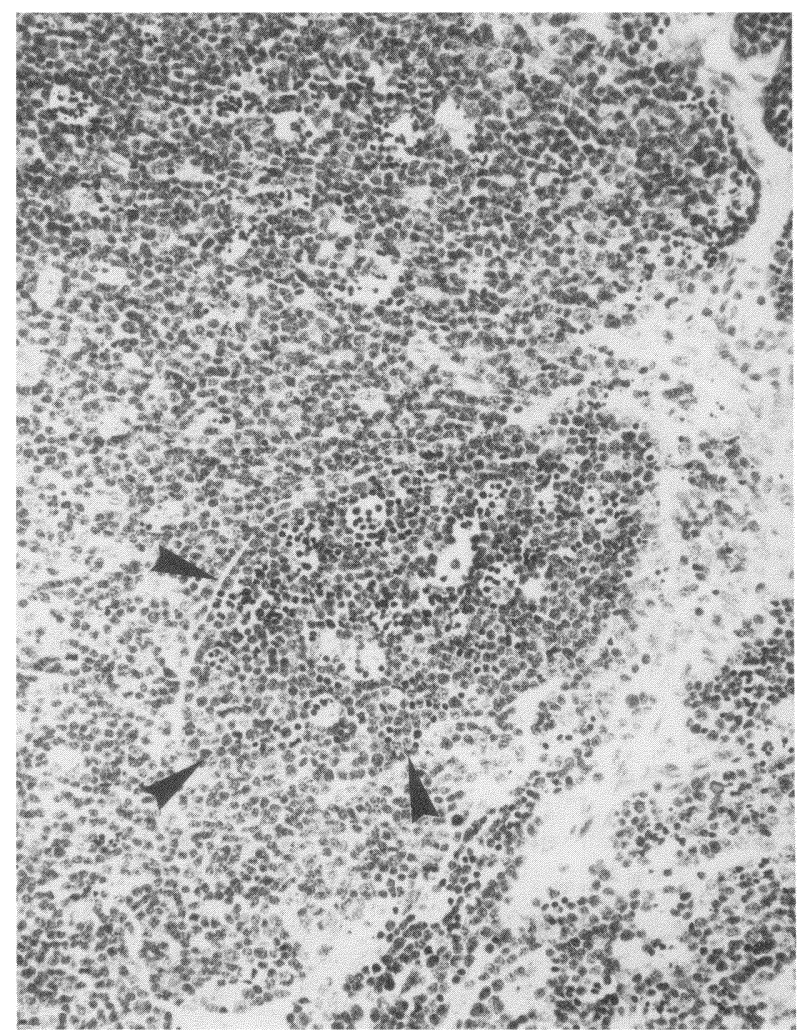

FIGURE 11. Thymus of rat treated with dexamethason (7days gavage study with $12 \mathrm{mg}$ dexamethason $/ \mathrm{kg}$ body weight). Tingible body macrophages in EFA (arrowiheads) and cortex. H\&E staining. $(\times 160)$.

rinsed again in PBS, incubated with the second antibody from Table 1, and again rinsed with PBS. Finally, the RAMPh complex was visualized using naphthol AS-BI phosphate and New Fuchsin, for $30 \mathrm{~min}$. The sections were not counterstained.

From one thymus, thirty serial sections $(7 \mu \mathrm{m}$ thick) were made. The slides were stained for MHC Class-II antigen (OX4; see Table 1) to follow the EFA in a block of approximately $0.25 \mathrm{~mm}$.

\section{Enzyme-Histochemistry}

Acid phosphatase activity was demonstrated according to Burstone (Pearse, 1968) with naphthol AS-BI phosphate (Sigma) as the substrate. The incubation time was $30-60 \mathrm{~min}$ at $37^{\circ} \mathrm{C}$. The substrate for the demonstration of nonspecific esterase was alpha-naphthyl acetate (Sigma; Pearse, 1972). Cryostat sections were used. Incubation time was 10-20 min at room temperature.

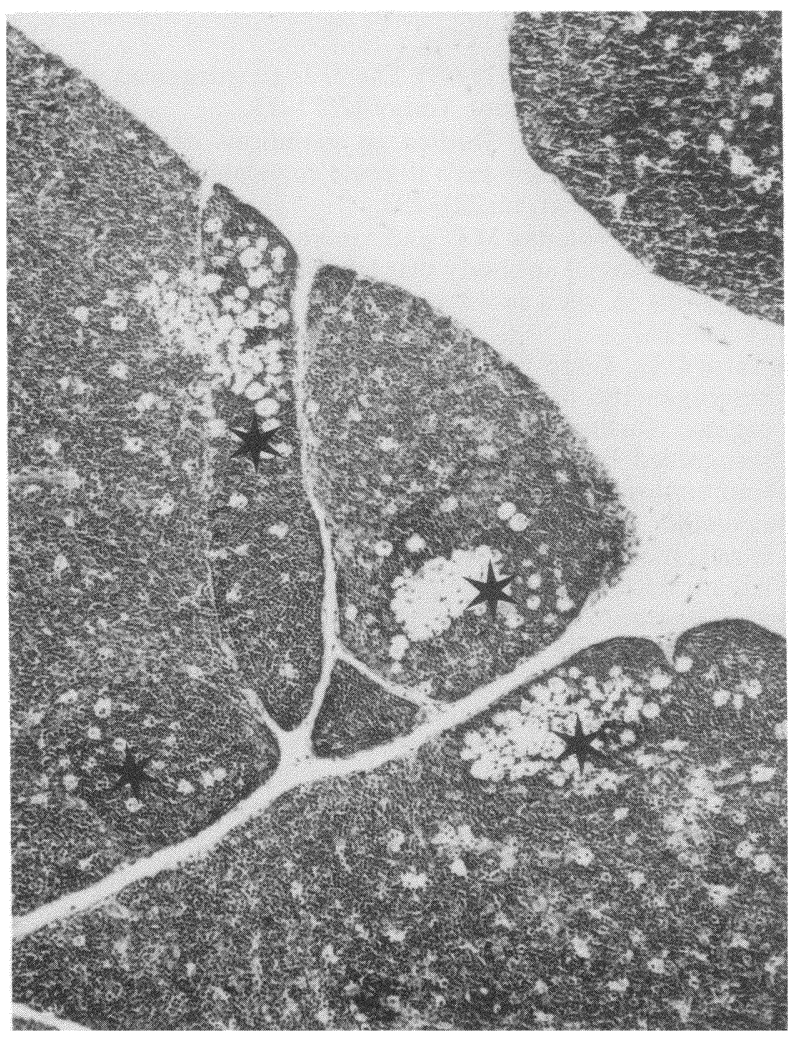

FIGURE 12. Thymus of rat treated with cyclosporin (14-days gavage study with $30 \mathrm{mg}$ cyclosporin $/ \mathrm{mg}$ body weight). Single, large macrophage like cells and aggregates of these cells in EFA $\left(^{*}\right)$. H\&E staining. $(\times 70)$.

For both reactions, hexazotized pararosaniline was used as the diazonium salt.

\section{ACKNOWLEDGMENTS}

We acknowledge greatly the gifts of the following monoclonal antibodies: Monoclonal antibodies in the ED series from C.D. Dijkstra, Free University of Amsterdam, The Netherlands; R73 from Th. Hunig, University of Wurzburg, Germany; monoclonal antibodies in the HIS series from J. Kampinga and F.G.M. Kroese, University of Groningen, The Netherlands; and antikeratins from F.C.S. Ramaekers, University Hospital Maastricht, The Netherlands. We thank A. Stenus-van Basten and S. de Vlugt-van den Koedijk for their help in preparation of the manuscript.

(Received August 11, 1992)

(Accepted October 21, 1992) 


\section{REFERENCES}

Boyd R.L., and Hugo P. (1991). Towards an integrated view of thymopoiesis. Immunol. Today 12: 71-79.

Christensen S. (1952). Studies on variations of the argyrophilic network in the rat's thymus correlated with the agegroups. Acta Anat. 16: 221-232.

Dallman M.J., Thomas M.J., and Green J.R. (1984). MRC OX19 a monoclonal antibody that labels rat $\mathrm{T}$ lymphocytes and augments in vitro proliferative response. Eur. J. Immunol. 14: $260-267$.

Dijkstra C.D., Döpp E.A., Joling P., and Kraal G. (1985). The heterogeneity of mononuclear phagocytes in lymphoid organs: Distinct macrophage subpopulations in the rat recognized by monoclonal antibodies ED1, ED2, ED3. Immunology 54: 589-599.

Duijvestijn A.M., Sminia T., Kohler Y.G., Janse E.M., and Hoefsmit E.C.M. (1982). Rat thymus micro-environment: An ultrastructural and functional characterization. In: In vivo immunology, Nieuwenhuis P., van den Broek A., and Hanna M.G., Eds. (New York: Plenum), pp. 441-446.

Godfrey D.I., Izon D.J., Tucek C.L., Wilson T.J., and Boyd R.L. (1990). The phenotypic heterogeneity of mouse thymic stromal cells. Immunology 70: 66-74.

Gratzner H.G. (1982). Monoclonal antibody to 5-bromo- and 5-iododeoxyuridine: A new reagent for detection of DNA replication. Science 218: 474-475.

Hunig T., Wallny H.J., Hartley J.K., Lawetzky A., and Tiefenthaler G. (1989). A monoclonal antibody to a constant determinant of the rat $\mathrm{T}$ cell antigen receptor that induces $\mathrm{T}$ cell activation. Differential reactivity with subsets of immature and mature T lymphocytes. J. Exp. Med. 169: 73-86.

Kampinga J. (1990). Thymocyte differentiation and thymic microenvironment development in the fetal rat thymus: An immunohistological approach. In: Thymus update 3: The role of the thymus in tolerance induction, Kendall M.D. and Ritter M.A., Eds. (London: Harwood Academic Publishers), pp. 149-187.

Kampinga J., Kroese F.G.M., Duijvestijn A.M., Murawska M.B., Pol G.H., and Nieuwenhuis P. (1987). The rat thymus microenvironment: Subsets of thymic epithelial cells defined by monoclonal antibodies. Transpl. Proc. 19: 3171-3174.

Kendall M.D. (1989). The morphology of perivascular spaces in the thymus. Thymus 13: 157-164.

Kroese F.G.M., Wubbena A.S., Opstelten D., Deenen G.J., Schwander E.H., de Leij L., Vos H., Poppema S., Volberda J., and Nieuwenhuis P. (1987). B lymphocyte differentiation in the rat: Production and characterization of monoclonal antibodies to B lineage associated antigens. Eur. J. Immunol. 17: 921-928.

Kuper C.F., Beems R.B., Bruijntjes J.P., Schuurman H.-J., and Vos J.' (in press). Thymus in adult and old rat. In: ILSI monograph on age-associated changes in laboratory animals. The Rat, Mohr U., Capen Ch., and Dungworth D., Eds. (Berlin: Springer Verlag).

McMaster W.R., and Williams A.F. (1979). Identification of Ia glycoproteins in rat thymus and purification from rat spleen. Eur. J. Immunol. 9: 426-433.

Milicevic N.M. and Milicevic Z. (1989). Histochemistry of the acutely involved thymus in nickel chloride-treated rats. J. Comp. Pathol. 101: 143-150.

Milicevic N.M., Milicevic Z., Colic M., and Mujovic S. (1987). Ultrastructural study of macrophages in the rat thymus, with special reference to the cortico-medullary zone. J. Anat. 150-89-98.

Moll R., Franke W.W., Schiller D.L., Geiger B., and Krepler R. (1982). The catalog of human cytokeratins: Patterns of expression in normal epithelia, tumors and cultured cells. Cell 32: 11-24.

Pearse A.G.E. (1968). Histochemistry. Theoretical and applied, vol. I., 3d ed. (New York: Churchill Livingstone).

Pearse A.G.E. (1972). Histochemistry. Theoretical and applied, vol II., 3d ed. (New York: Churchill Livingstone).

Ramaekers F.C.S., Huijsmans A., Schaart G., Moesker O., and Vooijs G. (1987). Tissue distribution of keratin 7 as monitored by a monoclonal antibody. Exp. Cell. Res. 170: 235-249.

Ramaekers F.C.S., Puts J.J.G., Moesker O., Kant A., Huijsmans A., Haag D., Jap P.H.K., Herman C.J., and Vooijs G.P. (1983). Antibodies to intermediate filament proteins in the immunohistochemical identification of human tumours: An overview. Histochem. J. 15: 691-713.

Rozing J., Coolen C., Tielen F.J., Weegenaar J., Schuurman H.-J., Greiner D.L., and Rossini A.A. (1989). Defects in the thymic epithelial stroma of diabetes prone BB rats. Thymus 14: $125-135$

Schuurman H.-J., Van Loveren H., Rozing J., Van Dijk A., Loeber J.G., and Vos J.G. (1990). Cyclosporin and the rat thymus. An immunohistochemical study. Thymus 16: 235-254.

Shi Y., Sahai B.M., and Green D.R. (1989). Cyclosporin A inhibits activation-induced cell death in $\mathrm{T}$ cell hybridomas and thymocytes. Nature 339: 625-626.

Steinmann G.G. (1986). Changes in the human thymus during aging. In: The human thymus, Muller-Hermelink H.K., Ed. (Berlin: Springer Verlag), pp. 43-89.

Van Ewijk W. (1984). Immunohistology of lymphoid and nonlymphoid cells in the thymus in relation to $\mathrm{T}$ lymphocyte differentiation. Amer. J. Anat. 170: 311-330.

Von Gaudecker B. (1986). The development of the human thymus microenvironment. Curr. Topics Pathol. 75: 1-39.

Williams A.F., Galfre G., and Milstein C. (1977). Analysis of cell surfaces by xenogeneic myeloma-hybrid antibodies. Differentiation antigens of rat lymphocytes. Cell 12: 633-673. 


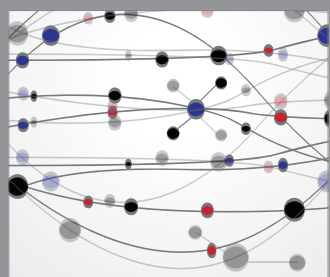

The Scientific World Journal
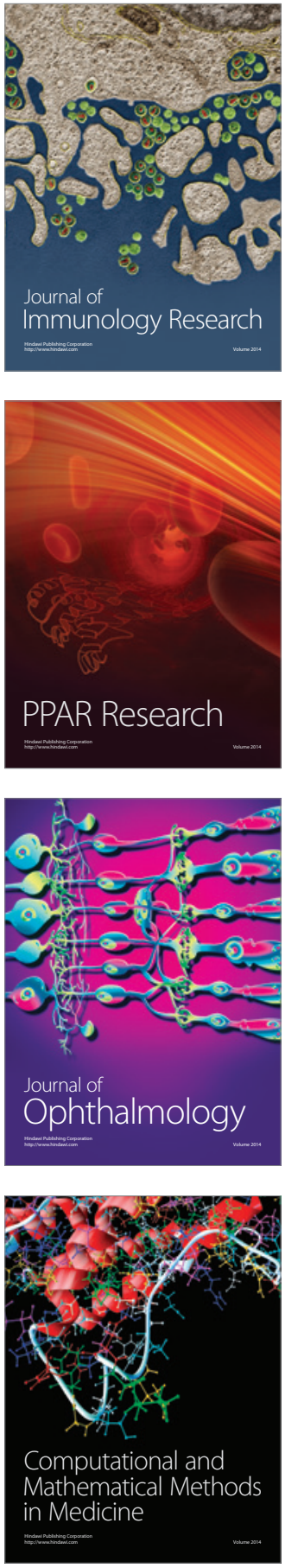

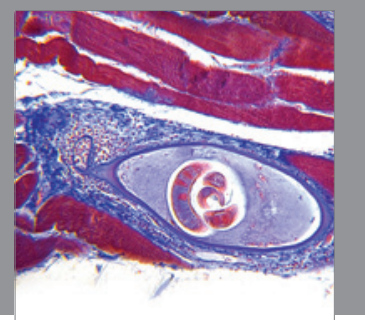

Gastroenterology

Research and Practice
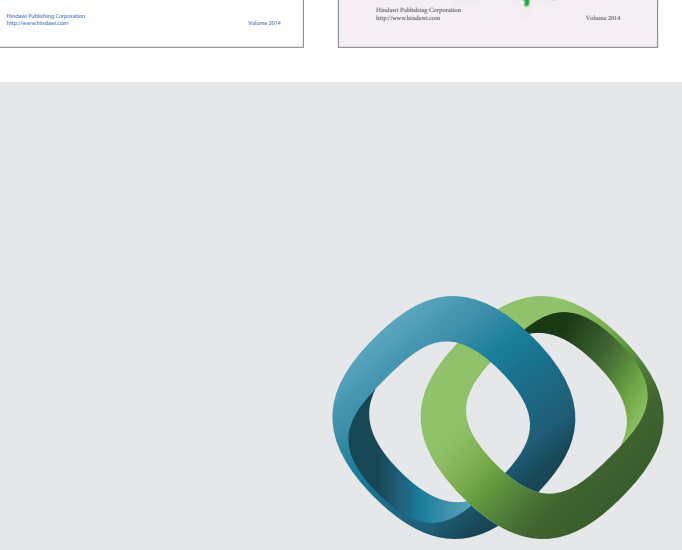

\section{Hindawi}

Submit your manuscripts at

http://www.hindawi.com
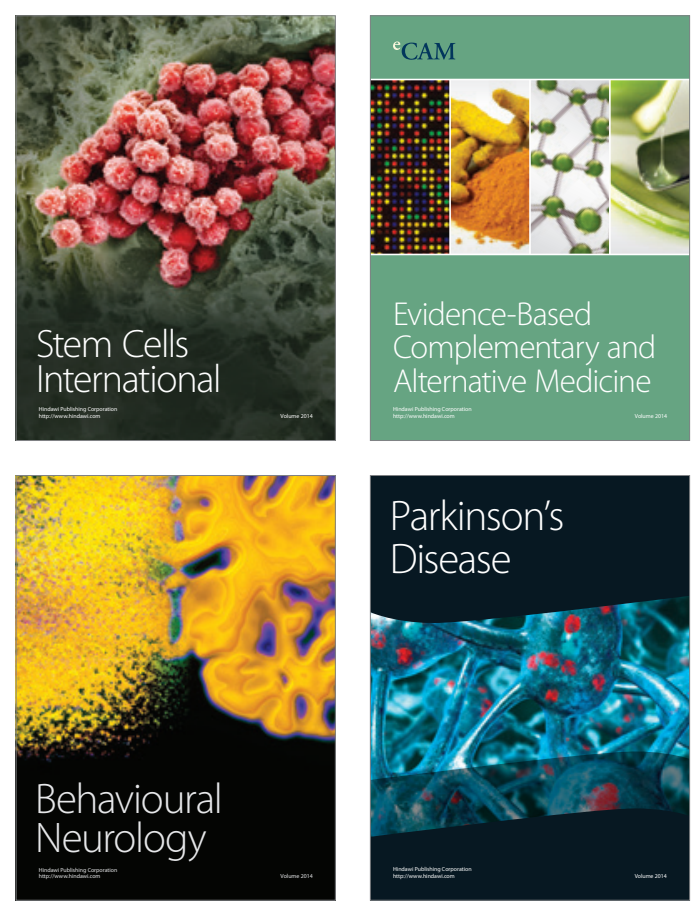

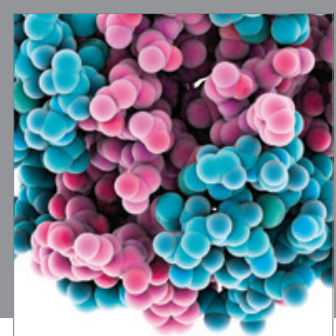

Journal of
Diabetes Research

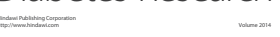

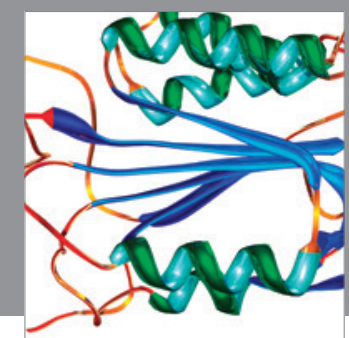

Disease Markers
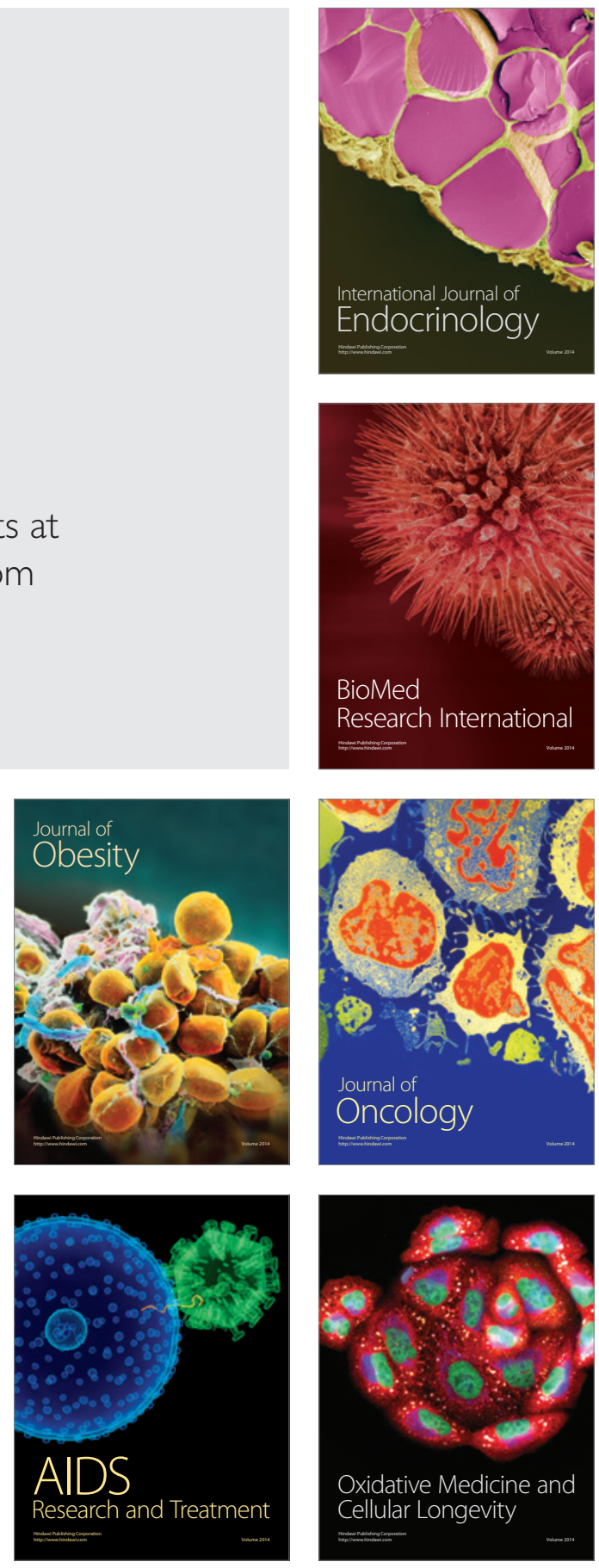